\title{
ANALISIS DETERMINAN PEMBERIAN KREDIT RITEL PADA PT. BANK BRI (PERSERO) TBK CABANG ABUNJANI SIPIN
}

\section{Bambang Nurdiansyah}

Universitas Jambi, Indonesia

Email: airafillahnurdiansyah@gmail.com

\begin{tabular}{l} 
INFO ARTIKEL \\
\hline Diterima \\
5 April 2021 \\
Direvisi \\
10 April 2021 \\
Disetujui \\
15 April 2021 \\
\hline
\end{tabular}

Keywords:

retail credit determinants; bri bank; small businesses
ABSTRACT
This study aims to determine the development of the influence of Third Party Funds (DPK), Capital Adequacy Ratio (CAR), Non Performing Loan (NPL), and Interest Rate (BI Rate) together and partially on retail lending. Track which research with multiple regression statistics analysis, which is a statistical analysis tool to find out for the influence of DPK, CAR, NPL and BI Rate (independent variables) on credit (dependent variables). The results showed that during theperiod 2014-2019 the amount of credit disbursed by PT. Bank BRI (Persero) Tbk, Abunjani Sipin branch experienced an average increase of $22.17 \%$, while the deposit of public funds at PT. Bank BRI (Persero) Tbk, Abunjani Sipin branch has experienced an average increase of $12.60 \%$ per year, while the value of CAR is $30.04 \%$, on the other hand in the same period the NPL value in PT. Bank BRI (Persero) Tbk. The effect of DEPOSIT (X1) on credit is positive, where every deposit increase of $1 \%$ then credit on PT. Bank BRI (Persero) Tbk, Abunjani Sipin branch will experience an increase of $4.374 \%$, on the other hand every CAR (X2) increase of $1 \%$ then the credit will decrease by $5.112 \%$, while every NPL increase of $1 \%$ then credit to PT. Bank BRI (Persero) Tbk. DPK, CAR, $N P L$ and BI Rate jointly and partially have a significant effect on credit at PT. Bank BRI (Persero) Tbk branch of Abunjani Sipin. The largest correlation coefficient value is 0.427, namely variable (DPK), followed by NPL and $B I$ Rate variable and lastly CAR variable.

\section{ABSTRAK}

Penelitian ini bertujuan untuk mengetahui perkembangan pengaruh Dana Pihak Ketiga (DPK), Capital Adequacy Ratio (CAR), Non Performing Loan (NPL), dan Suku Bunga (BI Rate) secara bersama-sama dan parsial terhadap penyaluran kredit ritel. Metode penelitian yang

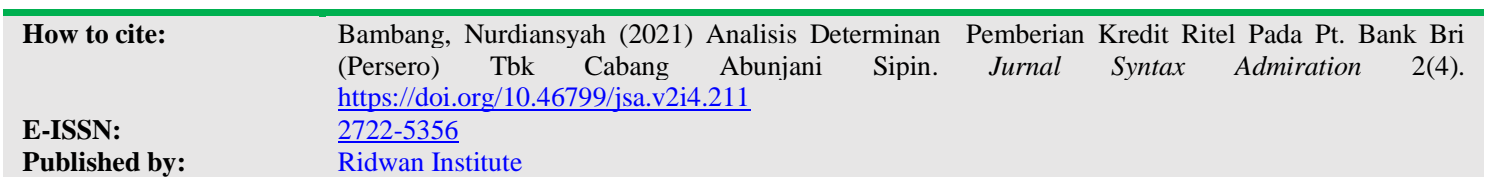




\section{Kata Kunci:}

determinan pemberian kredit ritel; bank bri; usaha kecil digunakan adalah dengan analisis statistik regresi berganda, yaitu alat analisis statistik yang digunakan untuk mengetahui pengaruh $D P K, C A R$, NPL dan BI Rate (variabel independent) terhadap kredit (variabel dependent). Hasil penelitian menunjukkan bahwa selama periode 2014-2019 jumlah kredit yang disalurkan oleh PT. Bank BRI (Persero) Tbk, cabang Abunjani Sipin mengalami peningkatan rata-rata sebesar $22,17 \%$, sementara simpanan dana masyarakat pada PT. Bank BRI (Persero) Tbk, cabang Abunjani Sipin telah mengalami peningkatan rata-rata sebesar $12,60 \%$ per tahun, sedangkan nilai CAR adalah sebesar 30,04\%, di sisi lain dalam periode yang sama nilai NPL pada PT. Bank BRI (Persero) Tbk. Pengaruh DPK (X1) terhadap kredit adalah positif, dimana setiap terjadi peningkatan DPK sebesar 1\% maka kredit pada PT. Bank BRI (Persero) Tbk, cabang Abunjani Sipin akan mengalami peningkatan sebesar 4,374\%, disisi lain setiap terjadi kenaikan CAR (X2) sebesar 1\% maka kredit akan turun sebesar 5,112\%, sementara setiap terjadi peningkatan NPL sebesar $1 \%$ maka kredit pada PT. Bank BRI (Persero) Tbk. DPK, CAR, NPL dan BI Rate secara bersama-sama maupun secara parsial berpengaruh signifikan terhadap kredit pada PT. Bank BRI (Persero) Tbk cabang Abunjani Sipin. Nilai koefisien korelasi yang terbesar adalah sebesar 0,427, yaitu variable (DPK), kemudian disusul variabel NPL dan BI Rate dan terakhir adalah variabel CAR.

\section{Pendahuluan}

Perkembangan perekonomian nasional dan perubahan lingkungan strategis yang dihadapi dunia usaha termasuk BRI dan usaha kecil menengah saat ini sangat cepat dan dinamis (Sulistyo \& Syafruddin, 2010). Bank Pembangunan Daerah sebagai badan usaha senantiasa harus diarahkan dan didorong untuk ikut berperan secara nyata meningkatkan pendapatan dan kesejahteraan masyarakat agar mampu mengatasi ketimpangan ekonomi dan kesenjangan sosial, sehingga lebih mampu berperan sebagai wadah kegiatan ekonomi rakyat (Dan Martono, 2011). Oleh karena itu, sudah saatnya untuk menempatkan sektor informal (seperti petani kecil di pedesaan, pedagang di pasar-pasar tradisional, penjual rokok, dan pedagang warung kelontong) di barisan terdepan dalam penetapan kebijakan Bank Indonesia (putting the last first) terkait dengan hal tersebut, serta dalam rangka pemberdayaan dan pengembangan sektor informal, maka peran dan kontribusi bank sebagai lembaga keuangan adalah pembiayaan sektor informal agar mampu berkembang lebih pesat (Kurniadi, 2012).

Berdasarkan laporan keuangan pada PT. Bank BRI (Persero) Tbk, cabang Abunjani Sipin dapat diketahui perkembangannya sebagai berikut: 
Tabel 1

Perkembangan Rata-rata Penyaluran Kredit Ritel pada PT. BRI (Persero) Cabang Abunjani Sipin Periode 2014 - 2019 (Tri Wulan I-III)

\begin{tabular}{ccccc}
\hline Tahun & $\begin{array}{c}\text { Target Kredit } \\
\text { (Rp. Juta) }\end{array}$ & $\begin{array}{c}\text { Realisasi Kredit } \\
\text { (Rp) }\end{array}$ & $\begin{array}{c}\text { Perkembangan } \\
\text { Realisasi (\%) }\end{array}$ & $\begin{array}{c}\text { Realisasi Kredit } \\
(\%)\end{array}$ \\
\hline 2014 & 60.000 .000 .000 & 48.291 .415 .595 & & 80,49 \\
2015 & 120.500 .000 .000 & 145.217 .679 .878 & 200,71 & 120,51 \\
2016 & 180.000 .000 .000 & 191.166 .720 .646 & 31,64 & 106,20 \\
2017 & 240.651 .000 .000 & 137.396 .350 .609 & $(28,13)$ & 57,09 \\
2018 & 210.942 .000 .000 & 171.482 .745 .796 & 28,81 & 81,29 \\
2019 & 180.000 .000 .000 & 164.818 .286 .667 & $(3,89)$ & 91,57 \\
\hline \multicolumn{2}{l}{} & & 37,52 & 89,53 \\
\hline
\end{tabular}

Sumber: PT. Bank BRI (Persero) Tbk, cabang Abunjani Sipin

Berdasarkan Tabel 1 dilihat bahwa rata-rata total kredit ritel pada PT. Bank BRI (Persero) Tbk, cabang Abunjani Sipin periode 2014 Triwulan I-III 2019. Pada tahun 2014 realisasi kredit ritel adalah sebesar Rp 48.291.415.595, dan pada tahun 2015 sebesar Rp 145.217.679.878 terjadi kenaikan sebesar 200,71\%, sedangkan pada tahun 2016 sebesar Rp 191.166.720.646, mengalami kenaikan 31,64\% tahun 2017 sebesar Rp. 137.396.350.609, terjadi kenaikan 127,58\% dan pada tahun 2018 sebesar Rp. 171.482.745.796, terjadi kenaikan $28,81 \%$ dari tahun sebelumnya, sementara hingga Triwulan ke III tahun 2019 kredit ritel yang disalurkan sudah mencapai Rp.164.818.286 .667, atau turun sebesar 3,89\% (Murdiyanto, 2021).

Meskipun realisasi kredit yang diberikan, khususnya kredit ritel mengalami peningkatan, pada kenyataannya belum sesuai dengan target yang telah dicanangkan oleh PT. Bank BRI (Persero) Tbk cabang Abunjani Sipin. Berbagai faktor yang menjadi pertimbangan dalam pemberian kredit oleh PT. Bank BRI (Persero) Tbk cabang Abunjani Sipin diantaranya adalah Dana Pihak Ketiga (DPK), Capital Adequacy Ratio (CAR), Non Performing Loan (NPL) dan BI Rate (Dwihandayani, 2018).

Dana Pihak Ketiga (DPK) berkaitan dengan sumber dana yang diperoleh oleh Bank BRI (Persero) Tbk, cabang Abunjani Sipin untuk dioptimalkan menjadi sumber kredit bagi nasabah. Adapun perkembangan DPK pada Bank BRI (Persero) Tbk, cabang Abunjani Sipin (Setiyaningsih et al., 2015).

Tabel 2

Perkembangan Dana Pihak Ketiga Pada PT. Bank BRI (Persero)Tbk, Cabang Abunjani Sipin Periode 2014-Triwulan III 2019

\begin{tabular}{ccc}
\hline Tahun & $\begin{array}{c}\text { DPK } \\
\text { (Rp. Juta) }\end{array}$ & $\begin{array}{c}\text { Perkembangan } \\
\text { Realisasi (\%) }\end{array}$ \\
\hline 2014 & 121.945 .465 .477 & - \\
2015 & 139.335 .302 .861 & 14,26 \\
2016 & 153.448 .018 .429 & 14,81 \\
2017 & 182.475 .818 .553 & 18,92 \\
2018 & 182.124 .060 .533 & $(0,19)$ \\
2019 & 189.169 .462 .632 & 3,87 \\
\hline Rata-rata & & 7,83 \\
\hline
\end{tabular}


Sumber: Laporan DPK Ritel PT. Bank BRI (Persero) Tbk, cabang Abunjani Sipin (Data diolah)

Berdasarkan pada table 2, dilihat bahwa rata-rata Dana Pihak Ketiga (DPK) pada PT. BRI (Persero) cabang Abunjani Sipin periode 2014-2019 Triwulan III. Pada tahun 2014 adalah sebesar Rp.121.945.465.477, dan pada tahun 2015 sebesar Rp 139.335.302.861 atau terjadi kenaikan 14,26\%, sedangkan pada tahun 2016 sebesar Rp 153.448.018.429 atau terjadi kenaikan 14,81\% kemudian pada tahun 2017 sebesar Rp 182.475.818.553 atau terjadi kenaikan $18,92 \%$ dan pada tahun 2018 sebesar Rp 189.169.462.632 atau terjadi kenaikan sebesar 10\% dan pada Triwulan III tahun 2019 jumlah DPK pada PT. BRI (Persero) cabang Abunjani Sipin adalah sebesar Rp. 189.169.462.632 atau meningkat sebesar 7,83\% (Wardiantika, 2014).

Peningkatan DPK di samping memberikan dampak terhadap meningkatnya kepercayaan masyarakat juga mendorong semakin membesarnya kapitalisasi bank sehingga dapat dimanfaatkan oleh pihak bank menjadi dana yang produktif (Agustinar, 2016). Hal ini pada akhirnya akan berdampak pada Capital Adeuacy Ratio (CAR) sebagaimana digambarkan pada tabel berikut:

Tabel 3

Perkembangan Rata-rata Capital Adequacy Ratio (CAR) pada PT. BRI (Persero) Cabang Abunjani Sipin Tahun 2014-Triwulan III 2019

\begin{tabular}{ccc}
\hline Tahun & NIlai CAR (\%) & $\begin{array}{c}\text { Perkembangan } \\
\text { Realisasi }(\%)\end{array}$ \\
\hline 2014 & 25,76 & - \\
2015 & 25,81 & 0,19 \\
2016 & 25,71 & $(0,39)$ \\
2017 & 26,06 & 1,36 \\
2018 & 22,25 & $(14,62)$ \\
2019 & 23,62 & 6,16 \\
\hline Rata-rata & & $(1,22)$ \\
\hline
\end{tabular}

Sumber : Annual Report BRI (Persero) cabang Abunjani Sipin

Berdasarkan pada tabel 3 dilihat bahwa rata-rata Capital Adeuacy Ratio (CAR) pada PT. BRI (Persero) cabang Abunjani Sipin. Pada tahun 2014 adalah sebesar 25,76\% dan pada tahun 2015 sebesar $25,81 \%$ terjadi peningkatan sebesar $0,19 \%$ sedangkan pada tahun 2016 sebesar $25,71 \%$ terjadi penurunan sebesar 0,39\%, kemudian pada tahun 2017 sebesar 26,06 terjadi peningkatan dari sebelumnya sebesar 1,36\% dan pada tahun 2018 sebesar $22,25 \%$ atau terjadi penurunan $14,16 \%$ dan pada tahun 2019 Triwulan ketiga adalah sebesar 23,62\% (Febrianti, 2015).

Nilai CAR yang cukup tinggi dan masih di atas ambang toleransi di atas $8 \%$ menunjukkan bahwa PT. BRI (Persero) cabang Abunjani Sipin tetap menjaga kehatihatian dalam pemberian kreditnya. Hal ini juga untuk menjaga agar kredit bermasalah dapat dikurangi atau di tekan di bawah 5\% di batas keamanan yang ditentukan oleh Bank Indonesia (Agustiningrum, 2012). Adapun di Wilayah kerja sumbagsel PT. BRI 
(Persero) cabang Abunjani Sipin termasuk salah satu cabang yang memiliki rasio NPL terendah sebagaimana tergambar pada tabel berikut:

\section{Tabel 4}

Perkembangan Nilai NPL PT. BRI (Persero) Cabang Abunjani Sipin Periode 2014- Tri wulan III 2019

\begin{tabular}{cccc}
\hline Tahun & $\begin{array}{c}\text { Realisasi Kredit } \\
(\mathbf{R p})\end{array}$ & Kredit Bermasalah (Rp) & NPL (\%) \\
\hline 2014 & 48.291 .415 .595 & $1,010,362,437$ & 2.09 \\
2015 & 145.217 .679 .878 & $500,955,457$ & 0.34 \\
2016 & 191.166 .720 .646 & $24,086,044,551$ & 12.60 \\
2017 & 137.396 .350 .609 & $3,646,311,640$ & 2.65 \\
2018 & 171.482 .745 .796 & $12,151,362,283$ & 7.09 \\
2019 & 164.818 .286 .667 & $16,466,358,106$ & 9.99 \\
\hline & Rata-rata & & 5,79 \\
\hline
\end{tabular}

Sumber : PT. Bank BRI (Persero) Tbk, cabang Abunjani Sipin

Berdasarkan Tabel 4, tergambar bahwa NPL pada PT. BRI (Persero) cabang Abunjani Sipin menunjukkan trend yang berfluktuasi, namun selama periode 2014-2019 nilai NPL PT. BRI (Persero) cabang Abunjani Sipin adalah sebesar 5,79\%, angka ini sudah termasuk cukup tinggi dan di atas batas toleransi Bank Indonesia sebesar 5\%, yakni memiliki nilai 5,79\%. Hal ini menunjukkan bahwa dalam pengelolaan kredit ritel PT. BRI (Persero) cabang Abunjani Sipin belum berjalan baik (Madri \& Mertha, 2015).

Besar kecilnya nilai kredit yang diberikan kepada masyarakat pada dasarnya juga sangat tergantung dari besar kecilnya kemampuan masyarakat dalam mengembalikan pinjamannya, maka dalam hal ini faktor suku bunga (BI Rate) turut mempengaruhi besar kecilnya kemampuan masyarakat dalam membayar pengembalian pinjaman (Zulifiah, 2014). Semakin besar beban bunga yang ditetapkan maka akan semakin membesar pula pembayaran pinjaman kepada Bank. Adapun perkembangan BI Rate tergambar pada tabel 5 berikut:

Tabel 5

Perkembangan Rata-Rata Suku Bunga (BI Rate) Periode 2014-Triwulan III 2019

\begin{tabular}{ccc}
\hline Tahun & SBI (\%) & Perkembangan (\%) \\
\hline 2014 & 9,65 & - \\
2015 & 6,26 & $(35.13)$ \\
2016 & 6,40 & 2.24 \\
2017 & 6,14 & $(4.06)$ \\
2018 & 7,15 & 16.45 \\
2019 & 6,18 & $(13,57)$ \\
\hline \multicolumn{2}{c}{ Rata-rata } \\
\multicolumn{2}{c}{ Sumber : Bank Indonesia, 2019}
\end{tabular}

Berdasarkan dari uraian diatas, maka peneliti tertarik untuk melakukan penelitian berjudul "Analisis Determinan Pemberian Kredit Ritel Pada PT. BRI (Persero) Cabang Abunjani Sipin".

Berdasarkan perumusan masalah di atas, maka dapat dirumuskan tujuan dari penelitian ini adalah sebagai berikut: 
1. Untuk mengetahui perkembangan pengaruh Dana Pihak Ketiga (DPK), Capital Adequacy Ratio (CAR), Non Performing Loan (NPL), dan Suku Bunga (BI Rate) secara bersama-sama terhadap penyaluran kredit Ritel pada PT. BRI (Persero) Tbk, cabang Abunjani Sipin Jambi.

2. Untuk mengetahui pengaruh DPK, CAR, NPL, dan BI Rate secara parsial terhadap penyaluran kredit ritel pada PT. BRI (Persero) cabang Abunjani Sipin Jambi.

3. Untuk mengetahui perkembangan variabel yang berpengaruh dominan terhadap penyaluran kredit pada PT. BRI (Persero) cabang Abunjani Sipin.

\section{Metode Penelitian}

Metode penelitian yang digunakan adalah dengan analisis statistik regresi berganda, yaitu alat analisis statistik yang digunakan untuk mengetahui pengaruh DPK, $C A R$, NPL dan BI Rate (variabel independent) terhadap kredit (variabel dependent). Untuk menggunakan teknik analisis ini terlebih dahulu dilakukan perubahan skala ke kala Z Score (satuan standar) karena skala pengukuran dalam penelitian ini tidak sama, metode pengumpulan data yang dipergunakan adalah Library Research (Penelitin Kepustakaan). Metode analisis data yang digunakan adalah Deskriptif Kualitatif, Deskriptif Kuantitatif dan Analisis Inferensial.

Selanjutnya digunakan analisis statistik regresi berganda, dengan rumus persamaan regresi sebagai berikut:

$$
\mathrm{Y}=\mathrm{a}+\mathrm{b}_{1} \mathrm{X}_{1}+\mathrm{b}_{2} \mathrm{X}_{2}+\mathrm{b}_{3} \mathrm{X}_{3}+\mathrm{b}_{4} \mathrm{X}_{4}+\mathrm{e}
$$

$\mathrm{Y}$ : Penyaluran kredit retail pada periode $\mathrm{t}$

$\mathrm{X} 1$ : DPK PT. Bank BRI (Persero)Tbk, cabang Abunjani Sipin pada periode $\mathrm{t}$

$\mathrm{X} 2$ : Capital Adequacy Ratio Bank Umum pada periode t-1

$\mathrm{X} 3$ : Non Performing Loan Bank Umum pada periode t-1

$\mathrm{X} 4$ : Suku Bunga SBI pada periode $\mathrm{t}$

Untuk melakukan uji hipotesis adapun yang digunakan adalah: uji statistik " $F$ ", uji statistik " $t$ " dan koefisien determinan, dengan rumus sebagai berikut:

$$
\begin{aligned}
\text { Rumus F hitung } & =\frac{R 2 /(k-1)}{1-R 2 /(n-k)} \\
\text { Rumus t hitung } & =\frac{\text { Koefisien Regeresi }}{\text { Standar Deviasi }}
\end{aligned}
$$

\section{Hasil dan Pembahasan}

Selama periode 2014-2019 jumlah kredit ritel yang disalurkan PT. Bank BRI (Persero) Tbk, cabang Abunjani Sipin menunjukkan kecenderungan yang terus meningkat dari tahun ke tahun, Selama periode 2014-2019 jumlah kredit ritel yang disalurkan oleh PT. Bank BRI (Persero) Tbk, cabang Abunjani Sipin mengalami peningkatan rata-rata sebesar $37,52 \%$. Angka ini mengalami perkembangan yang cukup 
tinggi, mengingat PT. Bank BRI (Persero) Tbk, cabang Abunjani Sipin masih berskala daerah dalam kegiatan perbankan di Provinsi Jambi.

PT. Bank BRI (Persero) Tbk, cabang Abunjani Sipin sangat menyadari bahwa upaya meningkatkan kemampuan keuangan tidak hanya dukungan dari kantor pusat Bank BRI dan kantor wilayah Bank BRI Palembang juga didukung oleh pemerintah daerah melalui masyarakat yang ada di Kota Jambi, akan tetapi potensi yang besar justru ada pada masyarakat, karena dana titipan hanya bersifat sementara dan dapat sewaktu-waktu ditarik oleh masyarakat sebagai debitur Bank. Untuk mampu meningkatkan penyerapan dana masyarakat PT. Bank BRI (Persero) Tbk, cabang Abunjani Sipin berupaya melakukan upaya yang lebih intens dengan melakukan berbagai kebijakan produk dan promosi yang bertujuan menarik minat masyarakat di Provinsi Jambi dan Kota Jambi khususnya (Sepang et al., 2018).

Secara keseluruhan selama periode 2014-2019 simpanan masyarakat pada PT. Bank BRI (Persero) Tbk, cabang Abunjani Sipin menunjukkan trend yang meningkat dari tahun ke tahun. Dimana secara rata-rata selama periode 2014-2019 laju peningkatan simpanan dana masyarakat pada PT. Bank BRI (Persero) Tbk, cabang Abunjani Sipin telah mengalami peningkatan rata-rata sebesar $7,83 \%$ per tahun. Peningkatan ini juga menunjukkan respon masyarakat yang semakin positif terhadap lembaga perbankan di Jambi, khususnya pada PT. Bank BRI (Persero) Tbk, cabang Abunjani Sipin sebagai lembaga yang dapat dipercaya (Nurdianti \& Ilyas, 2018).

Nilai CAR PT. Bank BRI (Persero) Tbk, cabang Abunjani Sipin tertinggi terjadi pada tahun 2017, yaitu sebesar 26,06\%. Hal ini berarti bahwa PT. Bank BRI (Persero) Tbk, cabang Abunjani Sipin memiliki cadangan yang mampu meminimalisir resiko dari cadangan modal sebesar 26,06\%. Angka ini sudah barang tentu sangat tinggi jauh di atas ketentuan dari Bank Indonesia yang menetapkan sebesar 8\% sebagai rasio terendah dalam melihat kesehatan suatu bank dari rasio kecukupan modal, namun demikian nilai CAR yang sangat tinggi juga mencerminkan banyaknya dana yang tidak dimanfaatkan secara optimal. Nilai CAR terendah pada PT. Bank BRI (Persero) Tbk, cabang Abunjani Sipin selama periode 2014-2019 terjadi pada tahun 2018, yaitu sebesar 22,25\%. Hal ini menunjukkan semakin besarnya upaya PT. Bank BRI (Persero) Tbk, cabang Abunjani Sipin dalam memanfaatkan dana yang dimilikinya untuk dikelola secara lebih produktif dan efisien. Secara rata-rata selama periode 2014-2019 nilai CAR pada PT. Bank BRI (Persero) Tbk, cabang Abunjani Sipin adalah sebesar 25,100\%, angka ini masih jauh di atas aturan Bank Indonesia dan mencerminkan tingginya tingkat kehati-hatian PT. Bank BRI (Persero) Tbk, cabang Abunjani Sipin dalam menyalurkannya dalam bentuk kredit ritel kepada masyarakat luas (Papalangi, 2013).

Non Performing Loans merupakan "rasio perbandingan kredit ritel yang bermasalah dengan total penyaluran dana yang disalurkan kepada masyarakat". Non Performing Loan (NPL) adalah "pembiayaan bermasalah yang terdiri dari pembiayaan yang berklasifikasi kurang lancar, diragukan dan macet". Terminologi NPL diperuntukkan bagi bank umum konvensional (Messai \& Jouini, 2013). 
Pembiayaan bermasalah berarti pembiayaan yang dalam pelaksanaannya belum mencapai atau memenuhi target yang diinginkan pihak bank seperti pengembalian pokok atau bagi hasil yang bermasalah kredit ritel yang memiliki kemungkinan timbulnya risiko di kemudian hari bagi bank kredit ritel yang termasuk golongan perhatian khusus, diragukan dan macet serta golongan lancar yang berpotensi terjadi penunggakan dalam pengembalian. NPL merupakan jenis dari rasio perbaikan aset (Prayudi \& Sragen, 2011).

Selama periode 2014-2019 nilai NPL pada PT. Bank BRI (Persero) Tbk, cabang Abunjani Sipin menunjukkan kecenderungan yang berfluktuasi secara rata-rata selama periode 2014-2019 nilai NPL pada PT. Bank BRI (Persero) Tbk, cabang Abunjani Sipin adalah sebesar 5,57\%. Angka ini sudah di atas rata-rata yang ditolerir oleh pihak manajemen, Harapan manajemen untuk target penurun NPL dimaksimalkan untuk penurun menjadi $3 \%$ per tahun.

Secara perlahan sejak tahun 2014 nilai BI Rate sudah lebih stabil karena di bawah $10 \%$, hal ini mencerminkan dari keinginan pemerintah dan memberikan peluang bagi dunia usaha untuk memanfaatkan dana perbankan agar kembali dapat membangkitkan sektor riil dan perusahaan dapat mengembangkan usahanya agar lebih produktif dengan dukungan dana dari pihak perbankan, sehingga akan berdampak terhadap meningkatnya aktivitas ekonomi di semua sektor (Jannah \& Nurfauziah, 2018).

Berdasarkan model persamaan regresi berganda memperlihatkan bahwa pengaruh DPK (X1) terhadap kredit adalah positif. Dimana setiap terjadi peningkatan DPK sebesar 1\% maka kredit ritel pada PT. Bank BRI (Persero) Tbk, cabang Abunjani Sipin akan mengalami peningkatan sebesar 4,374\%, disisi lain setiap terjadi kenaikan CAR (X2) sebesar 1\% maka kredit ritel pada PT. Bank BRI (Persero) Tbk, cabang Abunjani Sipin akan turun sebesar 5,112\%, sementara setiap terjadi peningkatan NPL sebesar 1\% maka kredit pada PT. Bank BRI (Persero) Tbk, cabang Abunjani Sipin akan turun sebesar 3,905\% dan setiap terjadi peningkatan BI Rate (X4) sebesar 1\% maka kredit akan turun sebesar $8,031 \%$. Hasil penelitian ini menunjukkan bahwa CAR, NPL dan BI Rate memberikan dampak negatif, sementara DPK memberikan dampak positif terhadap kredit pada PT. Bank BRI (Persero) Tbk, cabang Abunjani Sipin.

Secara teoritis dan hasil temuan memperlihatkan bahwa semua variabel memiliki pengaruh yang signifikan terhadap besar kecilnya pemberian kredit ritel pada PT. Bank BRI (Persero) Tbk, cabang Abunjani Sipin, namun demikian diantara keempat variabel yang diteliti terdapat variabel yang paling dominan dalam mempengaruhi pemberian kredit ritel pada PT. Bank BRI (Persero) Tbk, cabang Abunjani Sipin .

Berdasarkan hasil pengujian ternyata diperoleh nilai koefisien korelasi yang terbesar adalah sebesar 0,427, yaitu variabel Dana Pihak Ke tiga (DPK), kemudian disusul variabel NPL dan BI rate dan terakhir adalah variabel CAR. DPK sangat dominan dalam mempengaruhi pemberian kredit ritel pada PT. Bank BRI (Persero) Tbk, cabang Abunjani Sipin mengingat untuk memberikan dananya kepada masyarakat dalam bentuk pinjaman diperlukan dukungan yang sangat besar pula, oleh karenanya sangatlah wajar bila DPK merupakan variabel yang sangat dominan dalam 
mempengaruhi pemberian kredit ritel pada PT. Bank BRI (Persero) Tbk, cabang Abunjani Sipin.

\section{Kesimpulan}

Selama periode 2014-2019 jumlah kredit yang disalurkan oleh PT. Bank BRI (Persero) Tbk, cabang Abunjani Sipin mengalami peningkatan rata-rata sebesar 22,17\%, sementara simpanan dana masyarakat pada PT. Bank BRI (Persero) Tbk, cabang Abunjani Sipin telah mengalami peningkatan rata-rata sebesar $12,60 \%$ per tahun, sedangkan nilai CAR pada PT. Bank BRI (Persero) Tbk, cabang Abunjani Sipin adalah sebesar 30,04\%, di sisi lain dalam periode yang sama nilai NPL pada PT. Bank BRI (Persero) Tbk, cabang Abunjani Sipin adalah sebesar 0,40\% dan sejak tahun 2010 nilai BI Rate sudah di bawah $10 \%$, Hal ini mencerminkan dari keinginan pemerintah dan memberikan peluang bagi dunia usaha untuk memanfaatkan dana perbankan untuk kembali mengembangkan usahanya agar lebih produktif.

Pengaruh DPK (X1) terhadap kredit adalah positif, dimana setiap terjadi peningkatan DPK sebesar 1\% maka kredit pada PT. Bank BRI (Persero) Tbk, cabang Abunjani Sipin akan mengalami peningkatan sebesar 4,374\%, disisi lain setiap terjadi kenaikan CAR (X2) sebesar 1\% maka kredit pada PT. Bank BRI (Persero) Tbk, cabang Abunjani Sipin akan turun sebesar 5,112\%, sementara setiap terjadi peningkatan NPL sebesar 1\% maka kredit pada PT. Bank BRI (Persero) Tbk, cabang Abunjani Sipin akan turun sebesar 3,905\% dan setiap terjadi peningkatan BI Rate (X4) sebesar 1\% maka kredit akan turun sebesar $8,031 \%$. Hasil penelitian ini menunjukkan bahwa CAR, NPL dan BI Rate memberikan dampak negatif, sementara DPK memberikan dampak positif terhadap kredit pada PT. Bank BRI (Persero) Tbk, cabang Abunjani Sipin. DPK, CAR, NPL dan BI Rate secara bersama-sama maupun secara parsial berpengaruh signifikan terhadap kredit pada PT. Bank BRI (Persero) Tbk, cabang Abunjani Sipin.

Nilai CAR PT.Bank BRI (Persero) Tbk, cabang Abunjani Sipin selama periode 2014-2019 secara rata-rata diatas 20\%, dimana angka cukup aman atau batas aman yang lebih dari $8 \%$ sesuai dengan ketentuan Bank Indonesia. Hal ini menandakan bahwa perusahaan mengelola dana yang ada lebih produktif dikarenakan BRI cabang Abunjani Sipin secara organisasi dibawah Binaan Kantor Wilayah Palembang dapat mengontrol dan melakukan monitoring terhadap pertumbuhan dan penurunan CAR dikantor cabang BRI Abunjani Sipin. Nilai koefisien korelasi yang terbesar adalah sebesar 0,427, yaitu variabel Dana Pihak Ketiga (DPK), kemudian disusul variabel NPL dan BI Rate dan terakhir adalah variabel CAR. 


\section{BIBLIOGRAFI}

Agustinar, A. (2016). Analisis Pengaruh Dpk, Npf, Swbi Dan Surat Berharga Pasar Uang Syariah Terhadap Penyaluran Pembiayaan Perbankan Syariah Di Indonesia (Periode 2010-2014). Pascasarjana Uin-Su. Google Scholar

Agustiningrum, R. (2012). Analisis Pengaruh Car, Npl, Dan Ldr Terhadap Profitabilitas Pada Perusahaan Perbankan. E-Jurnal Manajemen, 2(8). Google Scholar

Dan Martono, A. H. (2011). Manajemen Keuangan. Edisi Kedua, Cetakan Pertama, Penerbit Ekonisia, Yogyakarta. Google Scholar

Dwihandayani, D. (2018). Analisis Kinerja Non Performing Loan (Npl) Perbankan Di Indonesia Dan Faktor-Faktor Yang Mempengaruhi Npl. Jurnal Ilmiah Ekonomi Bisnis, 22(3). Google Scholar

Febrianti, S. (2015). Analisis Pengaruh Pertumbuhan Gdp, Inflasi, Bi Rate Dan Nilai Tukar Terhadap Kredit Bermasalah Pada Bank Konvensional Dan Bank Syariah. Universitas Brawijaya. Google Scolar

Jannah, M., \& Nurfauziah, N. (2018). Analisis Pengaruh Nilai Tukar Rupiah, Tingkat Suku Bunga Sbi (Bi Rate) Dan Harga Emas Dunia Terhadap Indeks Lq45 Di Bursa Efek Indonesia. Jurnal Manajemen Maranatha, 17(2), 103-110. Google Scholar

Kurniadi, R. (2012). Pengaruh Car, Nim, Ldr Terhadap Return Saham Perusahaan Perbankan Indonesia. Accounting Analysis Journal, 1(1). Google Scholar

Madri, N. L. K. P. S., \& Mertha, I. M. (2015). Pengaruh Penerapan Corporate Governance, Dpk, Car Dan Npl Terhadap Profitabilitas Bank. E-Jurnal Akuntansi, 12(2), 154-171. Google Scholar

Messai, A. S., \& Jouini, F. (2013). Micro And Macro Determinants Of Non-Performing Loans. International Journal Of Economics And Financial Issues, 3(4), 852. Google Scholar

Murdiyanto, A. (2021). Faktor-Faktor Yang Berpengaruh Dalam Penentuan Penyaluran Kredit Perbankan Studi Pada Bank Umum Di Indonesia Periode Tahun 2006-2011. Conference In Business, Accounting, And Management (Cbam), 1(1), 61-75. Google Scholar

Nurdianti, I. T., \& Ilyas, F. (2018). Pengaruh Kolektivisme, Komitmen Organisasi, Dan Penalaran Moral Terhadap Intensi Melakukan Whistleblowing Pada Pt. Bank Bri (Persero), Tbk. Cabang Bengkulu. Jurnal Akuntansi, 8(1), 15-25. Google Scholar

Papalangi, R. S. (2013). Penerapan Spi Dalam Menunjang Efektivitas Pemberian Kredit Ukm Pada Pt. Bri (Persero) Tbk Manado. Jurnal Emba: Jurnal Riset Ekonomi, Manajemen, Bisnis Dan Akuntansi, 1(3). Google Scholar 
Prayudi, A., \& Sragen, S. (2011). Pengaruh Capital Adequacy Ratio (Car), Non Performing Loan (Npl), Bopo, Return On Asset (Roa) Dan Net Interest Margin (Nim) Terhadap Loan To Deposit Ratio (Ldr). Jurnal Likuiditas Perbankan. Google Scholar

Sepang, F. V, Manoppo, W. S., \& Mangindaan, J. V. (2018). Analisis Kinerja Keuangan Dengan Menggunakan Rasio Likuiditas, Solvabilitas Dan Profitabilitas Pada Pt. Bank Bri (Persero), Tbk. Jurnal Administrasi Bisnis (Jab), 7(2), 21-29. Google Scholar

Setiyaningsih, S., Juanda, B., \& Fariyanti, A. (2015). Faktor-Faktor Yang Memengaruhi Ratio Non Performing Loan (Npl). Jurnal Aplikasi Bisnis Dan Manajemen (Jabm), 1(1), 23. Google Scholar

Sulistyo, W. A. N., \& Syafruddin, M. (2010). Analisis Faktor-Faktor Yang Berpengaruh Terhadap Ketepatan Waktu Penyampaian Laporan Keuangan Pada Perusahaan Yang Listing Di Bursa Efek Indonesia Periode 2006-2008. Universitas Diponegoro. Google Scholar

Wardiantika, L. (2014). Pengaruh Dpk, Car, Npf, Dan Swbi Terhadap Pembiayaan Murabahah Pada Bank Umum Syariah Tahun 2008-2012. Jurnal Ilmu Manajemen (Jim), 2(4). Google Scholar

Zulifiah, F. (2014). Pengaruh Inflasi, Bi Rate, Capital Adequacy Ratio (Car), Non Performing Finance (Npf), Biaya Operasional Danpendapatan Operasional (Bopo) Terhadap Profitabilitas Bank Umum Syariahperiode 2008-2012. Jurnal Ilmu Manajemen (Jim), 2(3). Google Scholar

\section{Copyright holder :}

Bambang Nurdiansyah (2021)

First publication right :

Journal Syntax Admiration

This article is licensed under:

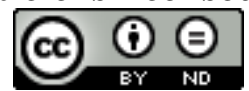

